\title{
VIDAL MARIN, Tomás, La impugnación de disposiciones sin fuerza de ley y resoluciones de las Comunidad Autónomas prevista en el artículo 161.2 de la Constitución. Tirant Lo Blanch, Valencia, 2020, 212 pp. ISBN 978-84-1355-263-7.
}

$$
\text { http://dx.doi.org/10.18543/ed-69(1)-2021pp293-302 }
$$

Resulta grato dar la bienvenida a nuevas obras que destacan la calidad jurídica de la doctrina constitucional española. Es para mi un honor poder hacer una recensión de esta obra del Profesor Tomás Vidal Marín puesto que es una de las personas que me ha visto crecer y madurar académicamente.

Espero encarecidamente que este trabajo cumpla con sus expectativas y que no desmerezca a lo que anticipo que es una gran obra de suma importancia en los tiempos que corren (sobre todo a raíz del caso catalán).

El tema abordado en esta monografía, como anticipaba, no es una cuestión baladí, sin embargo, pocos han sido los estudiosos del Derecho que se han atrevido a abordarla. La impugnación de disposiciones sin fuerza de ley y resoluciones de las Comunidades Autónomas previstas en el art. 161.2 de la $\mathrm{CE}$, es una materia compleja no exenta de polémica sobre todo al otorgar, produciendo un cierto desequilibrio, al Gobierno central la facultad de impugnar, por vicios de constitucionalidad, ante el Tribunal Constitucional todo tipo de resoluciones y disposiciones de la Comunidades $\mathrm{Au}-$ tónomas con el consiguiente efecto de suspensión automático; no siendo predicable dicho privilegio de los respectivos gobiernos autonómicos.

El Profesor Tomás Vidal Marín, tras una breve pero ilustrativa introducción, comienza su obra haciendo un estudio de la tramitación en las Cortes Constituyentes del art. 161.2 de la CE. En él hace patente como por influjo de la Constitución italiana de 1948 se previó en el art. 143 del Anteproyecto de Constitución española el «veto suspensivo» por parte del Gobierno Central de los textos aprobados por los respectivos Parlamentos autonómicos. Adicionalmente, el autor pone de manifiesto como, en su paso por la Ponencia, el mencionado art. 143 del Anteproyecto fue suprimido y sustituido por el art. 154.2 que tras el iter constituyente pasó a ser el actual art. 161.2 de la CE. Conviene destacar, como el propio autor pone en relieve, que el art. 154.2 es un precepto nuevo que NO es fruto de las enmiendas que se presentaron al texto del art. 143 del Anteproyecto. 
En el capítulo dedicado a los trabajos parlamentarios relativos al desarrollo del art. 161.2 de la Constitución española de 1978 en la Ley Orgánica del Tribunal Constitucional, el citado Profesor afirma que dicho desarrollo en la LOTC fue muy generoso puesto que además de servir de fundamento a un procedimiento autónomo (previsto en su Título V), también se extendió tanto al recurso de inconstitucionalidad como a los conflictos de competencias entre el Estado y las Comunidades Autónomas, y de las Comunidades Autónomas entre sí.

Sin embargo, como se puede extraer de la atenta lectura del capítulo en cuestión, el extenso desarrollo del art. 161.2 de la CE en la LOTC, a pesar del tenor literal que parece dar a entender que el Constituyente estaba configurando un proceso autónomo distinto de los establecido en el apartado primero del mencionado precepto, no fue objeto de disputa ni impugnación alguna por parte de los distintos grupos parlamentarios. Y, como advierte con audacia el autor, todo ello parece deberse a que, ante la incertidumbre que generaba el nuevo proceso de descentralización territorial que ponía en marcha la Constitución, el legislador orgánico intentó evitar cualquier funcionamiento anormal del mismo que fuese contrario a nuestra Carta Magna y, por ello, otorgó al Ejecutivo central el privilegio de instar la suspensión automática de toda actuación de las Comunidades Autónomas en el ámbito de los procedimientos constitucionales, sin perjuicio de que, en aras a evitar eventuales vulneraciones del principio de autonomía consagrado en la Norma
Fundamental, se atribuyó en último término al más alto de nuestro Tribunales la confirmación o revocación de la suspensión en cuestión.

En el capítulo relativo al significado y alcance del art. 161.2 de la CE, el Profesor Tomás Vidal Marín analiza de forma rigurosa la compatibilidad entre el art. $153 \mathrm{y}$ el art. 161.2 de la Constitución española. Pese a que $a$ priori podría observarse una contradicción entre lo preceptuado en los artículos en examen, estaríamos únicamente ante una contradicción aparente dado que el art. 161.2 de la CE se limita a matizar el control jurisdiccional sobre la actividad de los órganos autonómicos previsto en el art. 153.

Para reforzar esta afirmación establece una diferenciación con el fin de evitar un solapamiento en términos absolutos entre la jurisdicción contencioso-administrativa y la jurisdicción constitucional que eventualmente pudiese ocasionar el procedimiento regulado en el Título V de la LOTC. En este sentido, se llega a la conclusión de que si el vicio del acto sin fuerza de ley de la Comunidad Autónoma que origina el conflicto es un simple vicio de legalidad, será competente la jurisdicción contencioso-administrativa; no pudiendo conocer bajo ningún concepto el Tribunal Constitucional a pesar de la desafortunada redacción del art. 77 de la LOTC en virtud del cual: «la impugnación regulada en este Título, se cual fuere el motivo en que se base, se formulará...», pues de lo contrario «chocaría de frente» con la propia naturaleza jurídica del Alto Tribunal en tanto en cuanto es un tribunal de la constitucionalidad y en ningún caso de la legalidad. 
En cambio, si el vicio es de constitucionalidad, el autor se presunta si ¿podrá siempre el Gobierno central optar por la jurisdicción constitucional o por la jurisdicción contencioso-administrativa?

Y para dar respuesta a este interrogante, el autor determina que «dependerá en último término de la naturaleza y del tipo de la disposición o resolución autonómica impugnada». Afirmando que, si la resolución que se impugna es un reglamento ejecutivo de una ley, el litigio debería interponerse ante la jurisdicción contenciosoadministrativa, ya que la validez de este tipo de reglamentos está supeditada a la ley que desarrollan y no de la Constitución. Mientras que si se trata de un reglamento independiente sería competente el Tribunal Constitucional, puesto que si habría una relación de jerarquía entre la Norma Fundamental y este tipo de disposiciones.

Concluyendo que, en aquellos casos en los que el Gobierno pueda optar entre ambas jurisdicciones, resulta evidente que recurrirá a la jurisdicción constitucional habida cuenta de que conlleva la suspensión automática del acto o resolución recurrida.

Adicionalmente, en el citado capítulo, el autor realiza una delimitación del procedimiento previsto en el Título $\mathrm{V}$ de la LOTC respecto de otros procesos constitucionales, puesto que considera que es necesario acotar el proceso conflictual consagrado en el Título IV de la LOTC del reconocido en el Título V habida cuenta que ambos procesos tienen por objeto disposiciones y resoluciones sin fuerza de ley. Y, en este sentido, haciendo una interpretación lógico-sistemática de la
Constitución en relación con las competencia atribuidas al Tribunal Constitucional y con su ley orgánica de desarrollo, llega a la conclusión de que el procedimiento previsto en el Título V de la LOTC «ha de ponerse en marcha cuando el vicio constitucional de la disposición o resolución sin rango de ley que se impugna es extraño al reparto de competencias efectuado por el bloque de la constitucionalidad»; advirtiendo además que «tanto el Título IV como el Título V prevén la suspensión automática por lo que parece claro que en la voluntad del legislador no estaba presente la identificación del proceso previsto en el Título $\mathrm{V}$ con los conflictos de competencia».

Conviene matizar que, en la práctica, la gran mayoría de los vicios de inconstitucionalidad atribuidos a las disposiciones y resoluciones autonómicas sin rango de ley se identifican con vicios consecuencia de la conculcación del reparto de competencias entre el Estado y las Comunidades Autonómicas previsto en la Constitución española de 1978. Cuestión que, como pone en relieve el Profesor Tomás Vidal Marín, desplaza el proceso constitucional del Título $\mathrm{V}$ a un plano secundario, jugando un papel de cierre del control de constitucionalidad por parte del Tribunal Constitucional sobre las disposiciones objeto de estudio.

En cuanto a los órganos legitimados para su interposición, tras un riguroso análisis, el autor afirma que única y exclusivamente estaría legitimado el Gobierno central en virtud del art. 161.2 CE; puesto que en virtud del tenor literal del citado precepto 
constitucional sería inviable que el legislado orgánico pueda incrementar el número de sujetos legitimados activamente en este proceso en base a lo establecido en el art. 162.2 CE.

En el capítulo relativo al objeto del proceso, el Profesor Tomás Vidal Marín parte de la premisa de que nuestros constituyentes hicieron la formulación genérica del objeto del procedimiento impugnatorio previsto en el art. 161.2 de la CE al utilizar la expresión «disposiciones y resoluciones» adoptadas por las Comunidades Autónomas. Es decir, el autor matiza que nuestros constituyentes «no concretaron si la expresión disposiciones que emplea el art. 161.2 CE incluye a las disposiciones normativas con fuerza de ley y sin fuerza de ley, bien solo a las disposiciones sin fuerza de ley o bien solo a disposiciones con fuerza de ley. Fue el legislador orgánico el que ha resuelto esta cuestión puesto que al desarrollar de forma tan generosa dicho precepto constitucional ha considerado que el término disposiciones engloba tanto a las disposiciones sin fuerza de ley como a las disposiciones con fuerza de ley».

Centrándonos en el tema que nos ocupa, el Título V de la LOTC lleva por rúbrica «de la impugnación de disposiciones sin fuerza de ley y resoluciones de las Comunidades Autónomas prevista en el artículo 161.2 CE»; en consecuencia el autor, con gran acierto a mi parecer, considera susceptibles de impugnación por medio de dicho proceso autónomo cualquier norma reglamentaria, cualquier acto que ponga fin al procedimiento administrativo e, incluso, los actos de tramite a los que se refiere la Ley reguladora de la Jurisdicción Contencioso-administrativa.

En definitiva, pese a que de una somera lectura de la Ley Orgánica del Tribunal Constitucional podría llevarnos a discurrir que existen una identidad de objeto tanto en el proceso constitucional del Título $\mathrm{V}$ y el procedimiento relativo a los conflictos interterritoriales de competencias del Título IV, coincidiendo con el criterio del Profesor Tomás Vidal Marín, considero que no existe tal coincidencia plena. Todo ello debido a que, como se puede extraer de la atenta lectura de la monografía objeto de recensión, si bien es cierto que en la mayoría de las ocasiones el objeto de ambos procedimientos podría ser coincidente, no tendrían una identidad plena, probablemente, por el carácter diverso de ambos procedimientos constitucionales. Y, máxime, cuando de la propia LOTC parece configurar un objeto más amplio en el caso del proceso impugnatorio establecido en el Título IV $^{1}$.

En el capítulo sexto, el autor profundiza en estas cuestiones haciendo un exhaustivo análisis del control indirecto de la Ley autonómica a través del proceso impugnatorio del Título $\mathrm{V}$ de la LOTC y una especial consideración de los actos de trámite como objeto de impugnación.

${ }^{1}$ Frente al proceso constitucional del Título $\mathrm{V}$ en el que para la delimitación del objeto se refiere a «disposiciones sin fuerza de ley y resoluciones», en el Título IV se define como objeto del procedimiento constitucional en él consagrado las «disposiciones, resoluciones y actos». 
Respecto al primer aspecto, control indirecto de la Ley autonómica a través del proceso impugnatorio del Título V de la LOTC, el autor llega a la deducción de que es perfectamente factible en nuestro Derecho «un control indirecto de las leyes por medio de la impugnación de disposiciones sin fuerza de ley y resoluciones de las Comunidad Autónomas prevista en el art. 161.2 CE en base a una interpretación finalista y sistemática del artículo 77 de la LOTC el cual, aunque por remisión, permite el control indirecto de normas con rango de ley que sean contrarias a la Constitución». Con todo ello, dicha impugnación sólo será posible, como ha quedado patente, cuando el motivo de la inconstitucionalidad tenga su origen directo en «la norma con rango de ley y cuando esta norma se alegue expresamente en el proceso (exigencias estas contenidas en el art. 67 de la LOTC)»; sólo pudiendo prosperar aquellas pretensiones de declaración de ilegitimidad constitucional de la norma con rango de ley que estén vinculadas con el objeto de la impugnación.

En lo referente a la especial consideración de los actos de trámite como objeto de impugnación, tras un examen del Auto del Tribunal Constitucional 135/2004 en el que se rechazó la impugnación del Gobierno de la Nación contra el acuerdo del Gobierno del País Vasco por el que se aprobaba el conocido como Plan Ibarretxe (así como el acuerdo de la Mesa del Parlamento vasco por el que se admite a trámite dicha propuesta de reforma del Estatuto Político de la Comunidad de Euskadi para su tramitación de conformidad con el procedimiento legislativo ordinario), son varias las razones consistentes que aduce el autor, expuestas con toda claridad, para considerar equivocado dicho pronunciamiento constitucional.

En el capítulo dedicado al plazo para interponer la impugnación, se pone de manifiesto como la LOTC prevé dos criterios: por un lado, un criterio general según el cual se establece el plazo de 2 meses siguientes a la publicación; por otro lado, un criterio subsidiario en virtud del cual el plazo de 2 meses se empezará a computar, no desde la publicación, sino desde que el Gobierno de la Nación tuviera conocimiento de la misma. En este punto, el autor se pregunta: ¿Cuándo entrará en juego este criterio alternativo?

Según la Ley cuando no se publique la disposición normativa sin fuerza de ley o resolución de la Comunidad Autónoma. Nuestro ordenamiento jurídico solo obliga a que se publiquen en el Diario Oficial de la correspondiente Comunidades Autónomas las disposiciones normativas sin fuerza de ley de carácter general; luego, a sensu contrario, la falta de publicación se podrá producir en aquellos casos de disposiciones normativas que no tengan carácter general y en el supuesto de las resoluciones.

Ahora bien, como pone de manifiesto el Profesor Tomás Vidal Marín, este criterio subsidiario parece que no casa bien con el principio constitucional de seguridad jurídica, puesto que el art. 76 de la LOTC faculta al Gobierno Central para impugnar la disposición o resolución dicta sine die desde que la misma se haya dictado y notificado a la persona interesada. Es 
por ello por lo que este criterio debe interpretarse de manera restrictiva.

Es más, habida cuenta de lo criticable de este plazo alternativo, hubiera sido preferible, como afirmar con cierta perspicacia el autor, que el legislador hubiese omitido el mismo, estableciendo solo el plazo de 2 meses desde la publicación del acto impugnado.

Del atento examen del capítulo dedicado a los motivos de la impugnación se desprende que el ámbito propio y específico de este proceso constitucional queda delimitado por fundamentarse en cualquier vicio de inconstitucional, pero distinto a la infracción de la distribución constitucional de competencias.

El penúltimo capítulo, «procedimiento», se divide en cinco epígrafes que permiten al lector comprender de forma clara y concisa el procedimiento de impugnación consagrado en el art. 161.2 de la CE.

El primero, «La consulta obligada al Consejo de Estado como requisito de procedibilidad», el autor parte de la premisa de que «en este proceso constitucional, la consulta al Consejo de Estado ha de hacerse de forma obligada porque así lo exige la Ley reguladora del Consejo de Estado, en concreto la Ley 3/1980, de 22 de abril». Por todo ello, se puede afirmar que la consulta constituye un requisito de procedibilidad; y, en consecuencia, el autor considera que en caso de que el Gobierno central incumpla este requisito exigido legalmente, el Tribunal Constitucional deberá inadmitir a trámite la demanda que se formule, al incumplir el Gobierno un requisito necesario para la admisibilidad de la misma. Ahora bien, la opinión cualificada que emite el Consejo de Estado a través del dictamen correspondiente no tendrá carácter vinculante.

El segundo, «Invocación expresa del artículo 161.2 CE y diez a quo del inicio de la suspensión», comienza describiendo como el artículo 77 de la LOTC se remite, en lo que a la tramitación procesal del proceso constitucional objeto de estudio, al procedimiento previsto para los conflictos positivos de competencia; y en este último procedimiento, la Ley requiere la invocación expresa por el Gobierno del artículo 161.2 CE.

Probablemente sea esta remisión legal del Título $\mathrm{V}$ al Título IV la que ha dado lugar a que el alto Tribunal también exija la invocación expresa por parte del Gobierno de la Nación del artículo 161.2 CE para que se produzca la suspensión de la disposición sin fuerza de ley y de la resolución autonómica impugnada.

Al respecto, el Profesor Tomás Vidal Marín, sostiene que esta interpretación realizada por el Tribunal Constitucional es desacertada porque carece de lógica jurídica, ya que el máximo intérprete de la Constitución parece no tener suficientemente en cuenta que el legislador orgánico configuró en el Título $\mathrm{V}$ un proceso autónomo con fundamento en el artículo 161.2 CE. Y a tenor de este precepto constitucional, la impugnación por el Gobierno de la Nación de la disposición o resolución autonómica conlleva de forma automática su suspensión, lo cual viene ratificado por el art. 77 de la LOTC.

Una vez expuesto a lo anterior, conviene preguntarse ¿qué sucedería si el Gobierno Central impugnara, en 
base a lo dispuesto en el Título $\mathrm{V}$ de la LOTC, una disposición sin valor de ley de una Comunidad Autónoma y no invocase el art. 161.2 CE?

En este caso, de conformidad con la jurisprudencia del Tribunal Constitucional, se trataría de un procedimiento constitucional diferente al consagrado en el Título V; y, por ende, como apercibe acertadamente el autor ante «un proceso constitucional carente de cobertura legal y sin ningún fundamento constitucional.

Por otra parte, la admisión a trámite de la demanda es un requisito necesario para que produzca efectos la suspensión de la disposición o resolución impugnada, lo cual no es incompatible con el automatismo de la suspensión siempre y cuando se retrotraigan los efectos de la suspensión al momento de la interposición de la correspondiente demanda. La retroacción de los efectos de la suspensión al momento en que se formaliza la demanda afectará, como asevera el Profesor Tomás Vidal Marín, únicamente a las partes en el proceso impugnatorio, mientras que para los destinatarios, la suspensión iniciará su eficacia en el momento de su publicación en el Boletín Oficial del Estado.

El tercer epígrafe aborda la cuestión de la naturaleza de la suspensión muy polémica en la doctrina científica. En síntesis, la mayor parte de la doctrina y el Tribunal Constitucional español consideran que la suspensión prevista en el art. 161.2 CE es una medida que goza de una doble naturaleza: cautelar y de control del Estado sobre las Comunidades Autónomas.

Sin embargo, el Profesor Tomás Vidal Marín entiende que «incluso al inicio del procedimiento, la suspensión automática es una medida cautelar en el que fumus boni iuris y el periculum in mora se presumen ex constitutione; presunciones iuris tamtum que, a del citado Profesor, se podrían venir abajo si se probase, ante el Tribunal Constitucional, en el plazo de 5 meses la ausencia de algunos de esos presupuestos». Concluyendo que «solo una interpretación así sería congruente y respetuosa con la autonomía reconocida a nivel constitucional a las entidades territoriales que conforman el Estado español».

En cuanto a la duración de la suspensión automática, prevista en el epígrafe cuarto, si se atiende al tenor literal de los arts. 161.2 de la CE y 77 de la LOTC se puede deducir que el plazo de suspensión de 5 meses es un plazo máximo y, por tanto, la suspensión automática inicial no podrá prolongarse en ningún caso más allá de 5 meses desde la presentación de la demanda ante el Tribunal Constitucional; y si debe seguir suspendida en su vigencia la disposición o resolución autonómica impugnada, el autor considera que «habida cuenta que no haya resuelto aún mediante sentencia la impugnación de la disposición autonómica, será necesario un pronunciamiento expreso de aquel mediante auto en el que de forma motivada acuerde el mantenimiento de la suspensión». Y, posteriormente, expone la cuestionable doctrinal-jurisprudencial del Tribunal Constitucional entorno a la duración de la suspensión.

Por otro lado, partiendo del hecho de que la Constitución ha configurado el plazo máximo de 5 meses de duración de la suspensión automática deviene interesante preguntarse si el 
transcurso de dicho plazo sin que se haya pronunciado el Alto Tribunal, ¿producirá el levantamiento automático de la suspensión?

El autor es claro al emitir una respuesta negativa, puesto que entiende que la suspensión automática prevista en el art. 161.2 CE requiere de un pronunciamiento del Tribunal Constitucional al respecto, tal y como se desprende de la LOTC que en sus art. 77 y 64.2 requiere para que se produzca la suspensión, la comunicación por el Tribunal de la formulación de la impugnación o del conflicto positivo de competencia con invocación del citado precepto constitucional, lo que aparece justificado puesto que la suspensión se produce en el seno del proceso jurisdiccional.

En el último epígrafe de este capítulo, dedicado a los criterios para mantener o levantar la suspensión, se hace patente que el art. 161.2 de la CE no establece criterio alguno para que el Alto Tribunal adopte una decisión acerca del mantenimiento o levantamiento de la suspensión automática inicial, limitándose a señalar que, en el plazo máximo de 5 meses, el Tribunal deberá ratificarla o suspenderla. Y lo mismo sucede en el art. 77 de la LOTC, referido al proceso objeto de la monografía recensionada, y en el art. 65.2 LOTC, referido a los conflictos positivos de competencia planteados por el Gobierno central, los cuales al referirse a la suspensión automática afirman que la misma deberá ratificarse o levantarse por el Tribunal en plazo no superior a 5 meses.

Teniendo que recurrir a la jurisprudencia del Tribunal Constitucional para hallar los criterios a tener en cuenta para mantener o levantar la suspensión; jurisprudencia que, ante la indeterminación normativa, ha sido oscilante en sus primeros años, habiéndose perfeccionado y consolidado con el transcurrir de los años. Tales criterios son:

- Perjuicios de imposible o difícil reparación.

- Los intereses en juego o concernidos.

- La relevancia de la materia sobre la que incide la disposición autonómica impugnada.

- El principio de seguridad jurídica.

- El criterio del fumus boni iuris.

- El bloqueo de competencias estatales.

- Presunción de legitimidad de los actos o normas que emanan de los poderes públicos.

En opinión del autor, se aprecia como el Tribunal Constitucional a la hora de mantener o levantar la suspensión automática inicial prevista en el art. 161.2 CE, no se ha limitado a utilizar los clásicos criterios o requisitos que nuestro Derecho exige en relación con la adopción de medidas cautelares, básicamente, el periculum in mora y fumus boni iuris, sino que ha desarrollado una doctrina y jurisprudencia específica en atención a la particularidad de aquella suspensión.

En el último capítulo de su monografía, el Profesor Tomás Vidal Marín formula la siguiente cuestión: «iInfluye el auto del Tribunal decretando el mantenimiento o levantamiento de la suspensión sobre la sentencia que 
resolverá finalmente sobre el fondo del asunto?».

La jurisprudencia del Tribunal Constitucional al respecto ha sido clara puesto que en muchas ocasiones ha manifestado que: la resolución sobre el mantenimiento o levantamiento de la suspensión de las disposiciones, resoluciones y actos objeto de impugnación y procedentes de las Comunidades Autónomas prevista en el art. 161.2 de la CE es independiente de la resolución sobre el fondo del asunto, la cual deberá realizarse mediante sentencia. Doctrina del Tribunal Constitucional que, a juicio del autor, es poco discutible desde la perspectiva de la técnica jurídica y perfectamente congruente con el criterio que, con carácter general, emplea el Tribunal para decidir el mantenimiento o levantamiento de la suspensión: los perjuicios de imposible o difícil reparación.

No obstante, el autor en cuestión, estima que esta jurisprudencia «carece de la suficiente solidez cuando el Tribunal Constitucional utiliza otros criterios a los que ya nos hemos referido: bloqueo competencial, especial relevancia constitucional y fumus boni iuris. En estos casos, y a pesar de ser criterios considerados excepcionales por el Tribunal Constitucional, la decisión adoptada en el auto sobre el mantenimiento o levantamiento de la suspensión si prejuzgara el sentido del fallo posterior. En estos supuestos, la solución adecuada sería dictar sentencia en el plazo estipulado, sin emitir auto de ratificación de la suspensión de la actuación de la
Comunidad Autónoma puesto que, en caso contrario y por vía de excepción, podría llegar a desnaturalizarse el incidente de suspensión previsto en el art. 161. 2 de la CE».

Por último, no se puede ignorar el brillante prologo del Profesor Francisco Javier Díaz Revorio en el que, además de señalar la alta calidad de esta obra y elogiar la trayectoria académica del autor, sostiene que «esta anomalía útil y con sentido, y a pesar de las dudas, complejidades y contradicciones que introduce, se ha manejado en la práctica de forma razonable y conveniente como salvaguarda y protección de los valores constitucionales». Además, a pesar de coincidir con la mayoría de las opiniones vertidas por el Profesor Tomás Vidal Marín, el prologuista discrepa con alguna de ellas sobre todo en cuanto a la consecuencia de inadmisión por el Tribunal Constitucional de las pretensiones en las que el Gobierno no invoca expresamente la suspensión en un procedimiento del Título V; o, en la idea de que la suspensión pueda tener carácter retroactivo para las partes, pero no con alcance general.

En definitiva, en mi opinión, es una monografía altamente recomendable no sólo por la relevancia de la temática abordada, sino por las opiniones vertidas con una gran fundamentación que hacen casi irrebatibles las posturas adoptadas. Y, como no señalar, el riguroso y exhaustivo de la jurisprudencia en la materia y de las más relevantes obras doctrinales en la materia.

María Ruiz Dorado

Investigadora Doctora en Derecho Constitucional

Universidad de Castilla -La Mancha 


\section{VIDAL MARIN, Tomás, La impugnación de disposiciones sin fuerza de ley y resoluciones de las Comunidad Autónomas prevista en el artículo 161.2 de la Constitución. Tirant Lo Blanch, Valencia, 2020, 212 pp. ISBN 978-84-1355-263-7.}

http://dx.doi.org/10.18543/ed-69(1)-2021pp293-302

\section{Copyright}

Estudios de Deusto es una revista de acceso abierto, lo que significa que es de libre acceso en su integridad. Se permite su lectura, la búsqueda, descarga, distribución y reutilización legal en cualquier tipo de soporte sólo para fines no comerciales, sin la previa autorización del editor o el autor, siempre que la obra original sea debidamente citada y cualquier cambio en el original esté claramente indicado

Estudios de Deusto is an Open Access journal which means that it is free for full access, reading, search, download, distribution, and lawful reuse in any medium only for non-commercial purposes, without prior permission from the Publisher or the author; provided the original work is properly cited and any changes to the original are clearly indicated. 